\title{
Optics education through the Teacher Leaders in Research Based Science Education (TLRBSE) program
}

\section{Constance Walker, Stephen Pompea, Steven Croft}

Constance E. Walker, Stephen M. Pompea, Steven Croft, "Optics education through the Teacher Leaders in Research Based Science Education (TLRBSE) program," Proc. SPIE 9663, Eighth International Topical Meeting on Education and Training in Optics and Photonics, 966319 (6 October 2003); doi: $10.1117 / 12.2208461$

SPIE Event: Eighth International Topical Meeting on Education and Training in Optics and Photonics, 2003, Tucson, Arizona, United States 


\title{
Optics education through the Teacher Leaders in Research Based Science Education (TLRBSE) program
}

\author{
Constance E. Walker, Stephen M. Pompea, and Steven Croft \\ National Optical Astronomy Observatory, 950 N. Cherry Ave., Tucson, Arizona 85719 \\ telephone: 520-318-8535; fax: 520-318-8451; e-mail: cwalker@noao.edu
}

\begin{abstract}
Optics plays a large role in the National Optical Astronomy Observatory's Teacher Leaders in Research Based Science Education program by emphasizing optics and optical technology in preparation for an authentic research experience for teachers at Kitt Peak National Observatory. The goals and methodology of incorporating optics in this program will be discussed.

(C)2003 Optical Society of America

OCIS codes: (000.2060) Education; (350.1260) Astronomical optics
\end{abstract}

\section{Summary}

Optics plays a large role at the National Optical Astronomy Observatory and in its education program. In particular, its Teacher Leaders in Research Based Science Education program is a professional development program for teachers that emphasizes optics and optical technology.

The Teacher Leaders in Research-Based Science Education (TLRBSE) is a Teacher Enhancement Program funded by the National Science Foundation and hosted by the National Optical Astronomy Observatory in Tucson, AZ. Consistent with national priorities in education, TLRBSE seeks to retain and renew middle and high school teachers of science and mathematics by integrating the best practices of Research Based Science Education with the process of mentoring. Components of the program include 1) an on-line distance learning course to learn about astronomy, leadership skills, pedagogy, image processing and research-based science education; 2) an in-residence summer institute at Kitt Peak National Observatory engaging participants in an authentic research experience; 3) an extension of the research projects to the classroom with datasets and support provided by NOAO; and 4) a professional community of RBSE educators linked by on-line discussion forums and face-to-face presence at professional meetings.

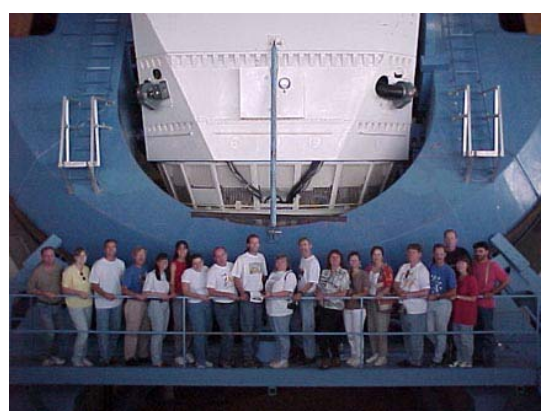

Fig. 1. TRBSE teachers at the 4-meter

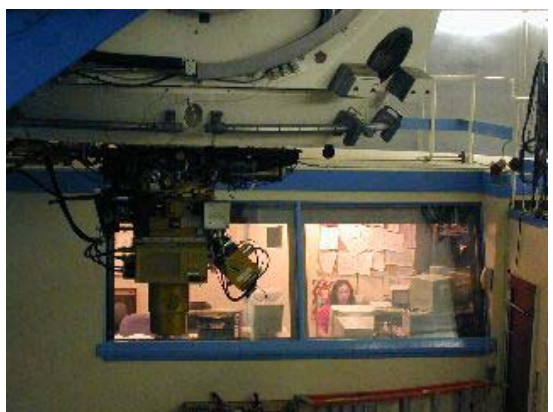

Fig. 2. CCD observing at the 2.1-meter

In particular, the distance learning component of the TLRBSE experience focuses on preparing the teachers for their authentic research experience using the telescopes on Kitt Peak (Fig. 1). In preparation, the teachers focus on two optics-related topics, key to astronomical observations: the principles of optics and the properties of telescopes and the astronomical detectors called charge-coupled devices (CCDs) (Fig. 2). The goal for the teachers (and hence their students) is to understand the basic "rules" of lenses and mirrors, understand how and why telescopes work, and become familiar with the basic properties of CCDs. Through their preparation and the ensuing mountain-top experience that enriches their lives, the teachers are also exposed to a multitude of related topics. These include spectroscopy, experimental design, spectroscope design, telescope design, collimation of optical systems, infrared and other detectors, filters, optical bench set-ups, Zeeman splitting, atmospheric transmission curves, optical depth, 
data taking, solar observing, nighttime observing, multi-wavelength astronomy, image processing, and, last but not least, misconceptions about optics.

The lessons learned here and how optics plays a central role in this education program will be discussed. For more information about TLRBSE, visit our website: http://www.noao.edu/outreach/tlrbse/. TLRBSE is funded by National Science Foundation grant NSF ESU 0101982. 